The Wilson Journal of Ornithology 122(2):381-384, 2010

\title{
Population status of chuck-will's-widow (Caprimulgus carolinensis) in the bahamas
}

\author{
William K. Hayes, ${ }^{1,4}$ Elwood D. Bracey, ${ }^{2}$ Melissa R. Price, ${ }^{1}$ Valerie Robinette,${ }^{1}$ \\ Eric Gren, ${ }^{1}$ and Caroline Stahala ${ }^{3}$
}

\begin{abstract}
The Chuck-will's-widow (Caprimulgus carolinensis) in the Bahama Islands has been regarded as a rare to uncommon winter visitor. We conducted breeding season surveys on the three largest northern islands (North Andros, Grand Bahama, and Great Abaco) to examine the status of this species. We encountered singing birds on most survey routes on all three islands, suggesting that sizeable breeding populations are widespread in the northern Bahamas with an aggregate estimate of $500-1,000$ pairs. Our density estimates were somewhat less than those from the primary range in the United States, suggesting either a lower carrying capacity in the Bahama Islands or recently established populations that have yet to reach carrying capacity. Received 24 August 2009. Accepted 3 January 2010.
\end{abstract}

Much remains to be learned about Chuckwill's-widow (Caprimulgus carolinensis) and other nightjars (Caprimulgiformes), largely because of their nocturnal and secretive habits. The species breeds across much of the eastern United States and winters in southern Florida, Central America, the West Indies, and northern South America. Gaps remain in our knowledge of the species' distribution, abundance, and habitat use despite its distinctive nocturnal song, which greatly facilitates detection (Straight and Cooper 2000). The species has gradually expanded its range in North America in the past century (Straight and Cooper 2000).

The status of Chuck-will's-widow in the Bahama Islands remains unclear. The species is considered a rare to uncommon winter visitor (Brudenell-Bruce 1975, Emlen 1977, Buden 1987, White 1998, Straight and Cooper 2000). Northrop (1891) collected a male with enlarged testes

\footnotetext{
${ }^{1}$ Department of Earth and Biological Sciences, Loma Linda University, Loma Linda, CA 92350, USA.

${ }^{2} 2305$ Royal Palm Way, Treasure Cay, Abaco, Bahamas.

${ }^{3}$ Department of Biological Science, Florida State University, Tallahassee, FL 32306, USA.

${ }^{4}$ Corresponding author; e-mail: whayes@1lu.edu
}

during breeding season (15 May) on Andros, but was uncertain of nesting. Paterson (1972) observed a bird incubating a single egg on Andros, but Bond (1973:3, 1984:20) rejected the record as a misidentified Antillean Nighthawk (Chordeiles gundlachii). However, Buden (1992) and Buden and Sprunt (1993) heard calling birds and flushed a pair during visits to several Exumas cays in April through June, suggesting possible breeding. Calling birds subsequently heard from February to July on several islands, documented in North American Birds seasonal reports, led to increased speculation of nesting. Breeding was eventually confirmed for Grand Bahama (Norton 1999; Norton and White 2001, 2002) and Abaco (Norton 2000). However, several questions remain unanswered. Were these breeding records extralimital, or indicative of larger breeding populations? If the latter, how large might these populations be, and how widespread are they?

The objective of our study was to clarify the population status of Chuck-will's-widow in the Bahama Islands. Our results, when compared to similar surveys from the species' continental range in the United States, provide inferences about the bird's abundance and breeding status.

\section{METHODS}

We conducted breeding season surveys on the three largest northern islands: North Andros, Grand Bahama, and Great Abaco. We followed generally practiced protocols for surveys of nightjars (e.g., Cooper 1981, Wilson 2008). Surveys were conducted along 8-20 km routes that included 9-12 brief stops (usually 10) of 25 min duration at $1 \mathrm{~km}$ or greater intervals. Surveys, with a few exceptions, were completed during $>50 \%$ moon illumination. Surveys were conducted during either the hour before sunrise or within 1-2 hrs following sunset, depending on when the moon was above the horizon. Weather varied from clear to overcast but with relatively low wind and absence of rain. We recorded the 
GPS (Global Positioning System) coordinates, time, and number of calling birds for each stop. We broadcast a recording of the song by speaker or whistled a cruder imitation of the song by mouth for most stops. We did not differentiate between spontaneous and solicited calls, as both were frequently detected. Calling birds could at times be heard at $>500 \mathrm{~m}$; we tried not to doublecount individuals on consecutive stops, but this may have resulted in slight underestimation bias.

We (MRP, VR, and EG) conducted seven surveys on North Andros during 2009. These included: 10 and 12 May (mornings) south of Nichol's Town; 17 May (morning) between Mastic Point and San Andros Airport; 2 June (evening) west of Stafford Creek; and 3, 4, and 5 June (evenings) between Stafford Creek and Love Hill. These routes traversed primarily Caribbean pine (Pinus caribaea) forest habitat with scattered openings, but coppice, marsh, and residential areas were present at some stops.

WKH conducted three surveys during 2007 on Grand Bahama. These included: 1 July (morning) from Bassett Cove to the oil storage facility east of Riding Point; 1 July (evening, 12 stops, no moonlight) near the water towers at Lucayan Estates; and 2 July (morning, 9 stops) in Lucaya along West Beach and Midshipman roads. All routes were in primarily pine forest with scattered openings; however, the first included occasional coppice and residential areas, and the third transected a rural residential area.

EB conducted repeated surveys along two routes (9 stops each) between Treasure Cay and Leisure Lee on Great Abaco during 2009. These included four evening surveys on 5 May, 10 May (no moonlight), 1 June, and 5 June. Additional evening surveys repeated in July and August yielded no calling birds and were excluded from analysis. Routes included pine forest with some coppice. CS conducted two surveys in 2009 further south on Great Abaco. These were 14 July (morning) along Great Abaco Highway between Crossing Rocks and Abaco National Park, and 15 July (morning) along Mid Road towards Hole-in-the-Wall. The routes passed through pine forest with variable understory, and several stops included coppice.

We derived the following variables for each route: total number of calling birds; mean birds per stop along route; proportion of stops with bird detections; number of birds calling per occupied stop (with birds calling); and density (pairs $/ \mathrm{km}^{2}$ ).
Numbers were adjusted for routes of 9 or 12 rather than 10 stops to reflect the standard 10 -stop route (i.e., birds/stop multiplied by 10). We assumed that all calling individuals were detected within a 500-m radius to estimate population density (calling males $=$ pairs $/ \mathrm{km}^{2}$ ). Thus, the number of calling birds detected at each stop corresponded to a minimum density of pairs per $0.785 \mathrm{~km}^{2}$ (area of circle with $500 \mathrm{~m}$ radius). This assumption is subject to several factors influencing detection rate, including some birds being heard at greater distances and many individuals not calling during the brief stops.

\section{RESULTS}

We encountered 42 calling birds along the 14 survey routes (Table 1). The number of calling birds per 10-stop route varied from zero to 12.2 . Calling birds were detected on four of the seven (57\%) Andros routes and on $100 \%$ of the three Grand Bahama and four Abaco routes. Grand Bahama appeared to host the highest density of individuals. One 9-stop route through a rural residential area yielded 11 calling birds. The maximum number of calling birds recorded per stop was two, and this was consistent for all three islands. Three birds were heard at several stops on Grand Bahama but, in each case, one was judged to be a bird heard at the previous stop and was not counted.

Repeated surveys along two routes on Great Abaco illustrated nightly and seasonal variation. Calling birds after sunset numbered four (5 May), five (10 May), six (1 Jun), and seven (5 Jun) for the 18 stops of both routes combined. No birds were detected on three additional surveys (22 and $30 \mathrm{Jul}, 5 \mathrm{Aug}$ ), and these surveys were excluded due to lateness of season. Our mean estimate of calling birds for the first four surveys (5.5) was $21 \%$ below the maximum count (7), suggesting detection of $79 \%$ or less for individual surveys.

\section{DISCUSSION}

Standardized surveys provide the best understanding of the relative abundance of Chuckwill's-widow, and only males are known to give the primary song (Straight and Cooper 2000). A number of factors can affect calling rates and influence detection rates and density estimates. Male calling peaks in late spring in continental populations and may decrease markedly in July (e.g., Cooper 1981, Straight and Cooper 2000). Both calling rate and duration of calling through- 
out the night increase significantly with greater moonlight (Cooper 1981, Mills 1986, Wilson and Watts 2006, Woods and Brigham 2008).

Our surveys suggest a substantial breeding population of Chuck-will's-widows exists on the large northern islands in the Bahamas. Abundance varied locally, but calling males were widespread on each of the large islands surveyed (North Andros, Grand Bahama, and Great Abaco). Birds calling in summer on New Providence (e.g., Norton and White 2002) and the Exumas (Buden 1992, Buden and Sprunt 1993) suggest breeding populations on these islands as well.

Relative densities from our surveys $(\bar{x}=0.14$ 0.56 birds/stop among the 3 islands) were generally lower than surveys within the primary range of continental populations. Cooper (1981), from 20 surveys in northern Georgia, reported 01.75 calling individuals per stop $(\bar{x}=1.37$ for 6 nights with $\geq 0.5$ lunar illumination). James and Neal (1986) listed counts of 1.77 and 2.32/stop in Searcy and Clay counties, Arkansas, respectively. Baumgartner and Baumgartner (1992) reported counts of 1.67 and 1.98/stop in northeast and southeast Oklahoma, respectively. More recently, Wilson (2008) reported on coordinated surveys from seven states having two or more surveys conducted in 2007. These included: Florida with 1.54 birds/stop, Alabama with 1.50, South Carolina with 1.30 , Georgia with 0.98 , Mississippi with 0.90 , Virginia with 0.44 , and North Carolina with 0.42 . Our surveys differed somewhat from those of Wilson (2008) in that stops were spaced more closely and listening time was briefer. We also used tape playback or vocal imitation to help stimulate calling.

We do not know whether the current breeding population in the Bahama Islands represents a recent colonization or has been overlooked. The relatively low densities compared to continental populations suggest either a lower carrying capacity in the Bahama Islands or recently established populations that have yet to reach carrying capacity. Population densities at the expanding northern periphery of the continental range are generally low (Hunt 2008). Future surveys could improve our knowledge on these possibilities. Two birds collected from Cuba during the breeding season with enlarged gonads suggest possible breeding there as well (Straight and Cooper 2000).

Our density estimates provide for a rough approximation of the total population in the 
Bahamas. The estimates are limited by three major factors (see also Wilson 2008): (1) some birds were detected at distances $>500 \mathrm{~m}$, resulting in overestimation; (2) not all males present were calling, resulting in underestimation; and (3) survey routes may not have been representative of the habitats available on each island. We suspect our numbers are underestimates. We multiplied our estimates by the quantity of suitable habitat on each island based on detailed maps. As many as 214 pairs exist on Andros (0.18 pairs $/ \mathrm{km}^{2} ; 5,957 \mathrm{~km}^{2}$ total area; $20 \%$ of total area assumed to be suitable habitat), 390 pairs on Grand Bahama (0.71 pairs $/ \mathrm{km}^{2} ; 1,373 \mathrm{~km}^{2}$ total area; $40 \%$ suitable habitat), and 192 pairs on Abaco (0.38 pairs $/ \mathrm{km}^{2}$; $1,681 \mathrm{~km}^{2}$ total area; $30 \%$ suitable habitat). New Providence $\left(207 \mathrm{~km}^{2}\right)$ presumably hosts a breeding population, and smaller populations may exist on other islands. We conclude the Bahama Islands supports an aggregate population in the vicinity of 500-1,000 pairs.

Clearly, the recent scattered reports of singing and nesting birds reflect sizeable breeding populations rather than extralimital records. Efforts should be undertaken to locate additional populations on other islands and to examine whether populations are gradually increasing in size.

\section{ACKNOWLEDGMENTS}

We thank the following for their support: Forfar Field Station and Insular Species Conservation Society (Andros research); Grand Bahama Power Company (Grand Bahama); and Bahamas National Trust and Friends of the Environment (Abaco).

\section{LITERATURE CITED}

Baumgartner, F. M. AND A. M. BAumgartner. 1992. Oklahoma bird life. University of Oklahoma Press, Norman, USA.

Bond, J. 1973. Supplement 18 to the Check-list of birds of the West Indies (1956). Academy of Natural Sciences of Philadelphia, Pennsylvania, USA.

Bond, J. 1984. Supplement 25 to the Check-list of birds of the West Indies (1956). Academy of Natural Sciences of Philadelphia, Pennsylvania, USA.

Brudenell-Bruce, P. G. C. 1975. The birds of New Providence and the Bahama Islands. Collins, London, United Kingdom.

Buden, D. W. 1987. The birds of the southern Bahamas.
British Ornithologists' Union, London, United Kingdom.

Buden, D. W. 1992. The birds of the Exumas, Bahama Islands. Wilson Bulletin 104:674-698.

Buden, D. W. AND A. SPRUnT IV. 1993. Additional observations on the birds of the Exumas, Bahama Islands. Wilson Bulletin 105:514-518.

CoOper, R. J. 1981. Relative abundance of Georgia caprimulgids based on call-counts. Wilson Bulletin 93:363-371.

EMLEN, J. T. 1977. Landbird communities of Grand Bahama Island: the structure and dynamics of an avifauna. Ornithological Monographs 24.

HunT, P. 2008. Northeast nightjar survey: 2008 results. Report to the New Hampshire Audubon Society. www. vtecostudies.org/PDF/Nightjar08.pdf (accessed $4 \mathrm{Au}$ gust 2009).

JAMES, D. A. AND J. C. NEAL. 1986. Arkansas birds: their distribution and abundance. University of Arkansas Press, Fayetteville, USA.

MilLs, A. M. 1986. The influence of moonlight on the behavior of goatsuckers (Caprimulgidae). Auk 103:370-378.

NORTHROP, J. I. 1891. The birds of Andros Island, Bahamas. Auk 8:64-80.

NoRton, R. L. 1999. West Indies Region. North American Birds 53:436-437.

Norton, R. L. 2000. West Indies. North American Birds $54: 426-427$

Norton, R. L. AND A. White. 2001. West Indies. North American Birds 55:370-372.

Norton, R. L. AND A. White. 2002. West Indies. North American Birds 56:496-497.

PAterson, A. 1972. Nesting of Chuck-will's-widow on Andros Island, Bahamas. Auk 89:676-677.

Straight, C. A. AND R. J. CoOPER. 2000. Chuck-will'swidow (Caprimulgus carolinensis). The birds of North America. Number 499.

White, A. W. 1998. A birder's guide to the Bahama Islands (including Turks and Caicos). American Birding Association, Colorado Springs, Colorado, USA.

WiLSON, M. D. 2008. The Nightjar Survey Network: program construction and 2007 Southeastern Nightjar Survey results. Center for Conservation Biology Technical Report Series, CCBTR-08-001, College of William and Mary, Williamsburg, Virginia, USA.

Wilson, M. D. AND B. D. WATTS. 2006. The effect of moonlight on detection of Whip-poor-wills: implications for long-term monitoring strategies. Journal of Field Ornithology 77:207-211.

Woods, C. P. AND R. M. BRIGHAM. 2008. Common Poorwill activity and calling behavior in relation to moonlight and predation. Wilson Journal of Ornithology 120:505-512. 